3. Aris A. Controlled exsanguination during sternal reentry. J Thorac Cardiovasc Surg. 2003;126:918-9.

4. Gazzaniga AB, Palafox BA. Substernal thoracoscopic guidance during sternal reentry. Ann Thorac Surg. 2001;72:289-90.
5. Ismail I, Zhang R, Ringe K, Fischer S, Haverich A. Retrosternal adhesiolysis through an anterior minithoracotomy: a novel approach facilitating complete median redo sternotomy with a patent internal thoracic artery graft. $J$ Thorac Cardiovasc Surg. 2009;137:1034-5.

\title{
Secure anastomosis for damaged aortic root reconstruction: Graft insertion technique
}

\author{
Yoshitsugu Nakamura, MD, ${ }^{a}$ Osamu Tagusari, MD, ${ }^{a}$ Junjiro Kobayashi, MD, ${ }^{\mathrm{b}}$ and Hiroyuki Nakajima, MD, ${ }^{\mathrm{b}}$ \\ Tokyo and Osaka, Japan
}

Bleeding from the proximal anastomosis is a devastating complication after aortic root replacement. Especially in situations requiring reoperation of the aortic root or situations involving prosthetic valve endocarditis (PVE), damage, an irregularly shaped annulus, or inflammation in the surrounding tissue makes the proximal anastomosis technically demanding. ${ }^{1,2}$ We describe a novel graft insertion technique that can be used in such complicated cases. Our technique provides a reliable double-suture placement to reinforce the proximal anastomosis.

\section{CLINICAL SUMMARY}

Through a median sternotomy, the aortic root is dissected, and cardiopulmonary bypass is established in the usual manner. After crossclamping of the aorta, the prosthesis is removed, and coronary ostia are trimmed. In cases of PVE, aggressive debridement of the infected tissue around the aortic root is carried out. An inverted tube graft with a diameter the same as that of the left ventricular outflow tract (LVOT) and a length of $3 \mathrm{~cm}$ is inserted into the LVOT (Figures 1, $A$, and 2, A). Nine to 12 horizontal mattress sutures are placed from inside the inserted graft to the epicardial side with $2-0$ synthetic braided and pledgeted sutures (Figure 1, B). Then the seam is reinforced with running over-and-over suturing of the edges of the LVOT and the graft with 4-0 polypropylene sutures (Figures $1, C$, and 2, B). This completes a double-suture reconstruction for the proximal anastomosis. Next, the tube graft inserted into the LVOT

From the Department of Cardiovascular Surgery, ${ }^{\mathrm{a}}$ NTT Medical Center, Tokyo; and the Department of Cardiovascular Surgery, ${ }^{\mathrm{b}}$ National Cerebral and Cardiovascular Center, Osaka, Japan.

Disclosures: Authors have nothing to disclose with regard to commercial support.

Received for publication Jan 8, 2011; revisions received Feb 15, 2011; accepted for publication Feb 25, 2011; available ahead of print April 1, 2011.

Address for reprints: Yoshitsugu Nakamura, MD, Department of Cardiovascular Surgery, NTT Medical Center Tokyo, 5-9-22 Higashigotanda, Shinagawa-ku,

Tokyo 141-8625, Japan (E-mail: ystgnkmr@gmail.com).

J Thorac Cardiovasc Surg 2011;142:948-50

0022-5223/\$36.00

Copyright (C) 2011 by The American Association for Thoracic Surgery

doi:10.1016/j.jtcvs.2011.02.032 is pulled out, making it right-side-out again (Figures $1, D$, and $2, C$ ), and then cut so that $5 \mathrm{~mm}$ of the length remains. Next, a composite graft with a short flange or a stentless aortic valve is sewn to the graft anastomosed to the LVOT with a continuous suture (Figure 1,E). Coronary ostia are reimplanted into the composite graft by using either the button technique or the graft $(10 \mathrm{~mm})$ interpose technique (Figure 1,F). Finally, the distal end of the composite graft is anastomosed to the ascending aorta.

Since 2002, we have performed aortic root replacement with this technique in 6 complicated reoperations: 2 pseudoaneurysms and 1 bioprosthetic valve failure after aortic root replacement and 3 cases of PVE (mechanical valve, $\mathrm{n}=2$; stentless bioprosthetic valve, $\mathrm{n}=1$ ). The grafts that were used for redo surgery were composite grafts with a mechanical valve in 2 cases, a composite graft with a stented bioprosthetic valve in 1 case, and stentless aortic valves in 3 cases. Concomitant procedures were tricuspid valve repairs in 2 cases and quadruple coronary artery bypass grafting in 1 case. Mean crossclamp and cardiopulmonary bypass times were $189 \pm 44$ and $279 \pm 38$ minutes, respectively. No additional stitching was necessary for hemostasis of the proximal anastomosis in any patient. No complete heart block or re-exploration was seen. During the mean followup time of $52 \pm 31$ months, there was 1 early death caused by respiratory failure and 1 late death caused by liver cirrhosis 41 months after surgical intervention. None of the patients have undergone a further reoperation for any cause.

\section{DISCUSSION}

Bleeding from the proximal anastomosis is the most common complication in reoperation on the aortic root. It has been reported that the incidence of early reintervention for excessive bleeding is high $(5 \%$ to $15 \%))^{1,2}$ In reoperation the aortic annulus and surrounding tissue are often irregular and insecure for performing a proximal anastomosis because of adhesion, inflammation, or debridement. We therefore created a graft insertion technique for the proximal anastomosis for such complicated cases. This technique is 


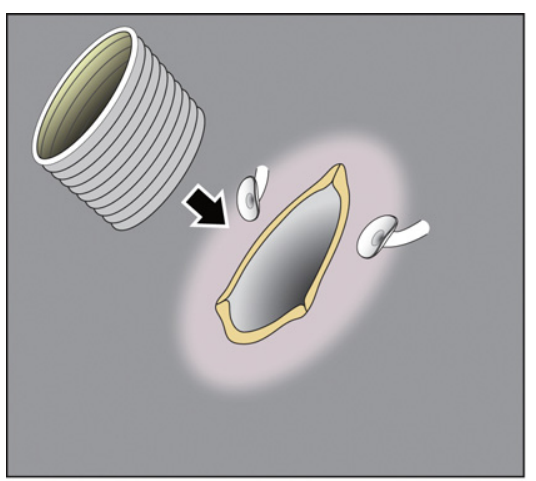

A

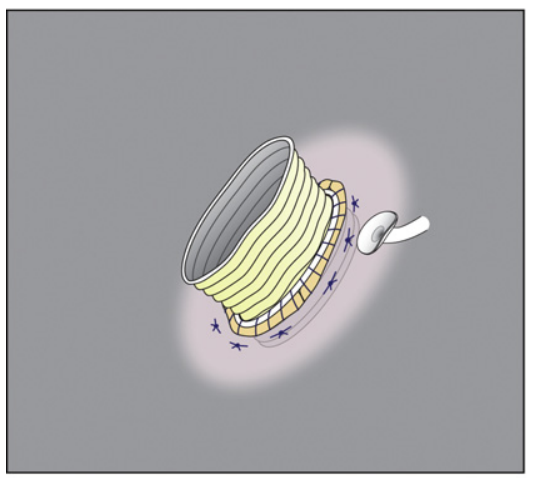

D

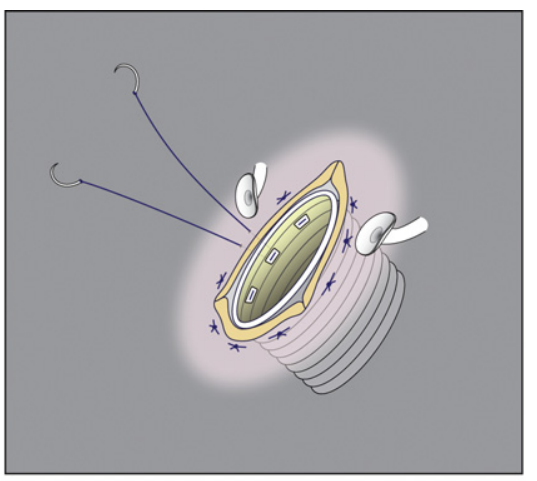

B

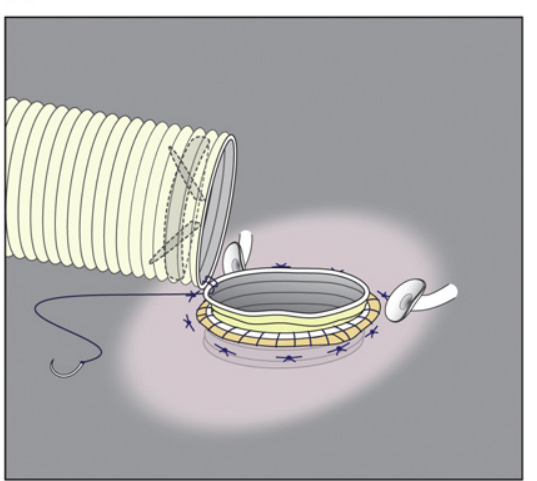

$\mathbf{E}$

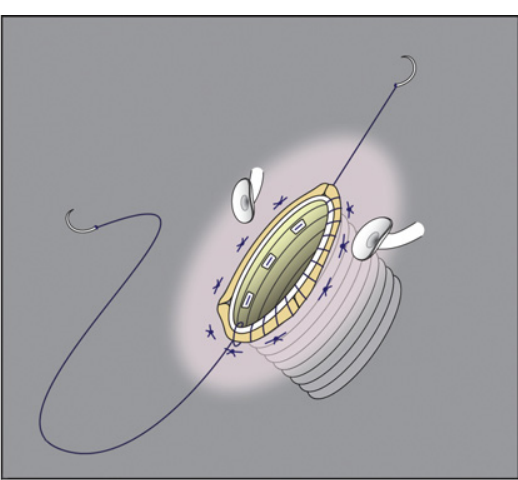

C

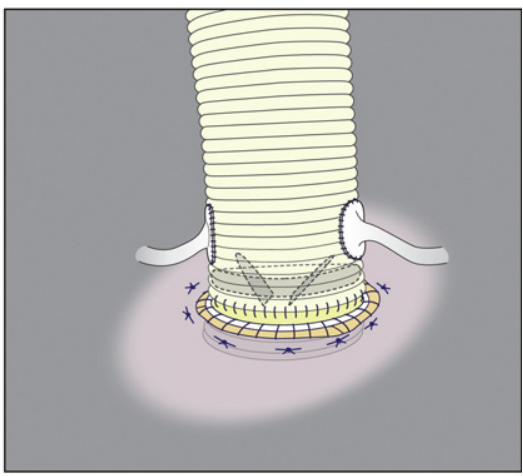

$\mathbf{F}$

FIGURE 1. Schematic diagram showing the steps of a new technique for proximal anastomosis of the aortic root with a graft insertion. A, An inverted tube graft of the same diameter as the left ventricular outflow tract (LVOT) and $3 \mathrm{~cm}$ in length is inserted into the LVOT. B, Nine to 12 horizontal mattress sutures are placed from inside of the inserted graft to the epicardial side. C, The seam in panel B is reinforced with a running over-and-over suture of the edges of the LVOT and the inserted graft. D, The inserted tube graft is pulled out from the LVOT. E, The graft is shortened, leaving $5 \mathrm{~mm}$ of the length. Then a composite graft with a short flange or a stentless aortic valve is sewn onto the graft anastomosed to the LVOT. F, Coronary ostia are reimplanted to the composite graft.

performed on a completely everted anastomosis between the graft and the LVOT. As such, it provides secure double-suture placement, an excellent surgical view, and ample working space. We have also used this graft inversion technique for apicoaortic bypass and have had excellent hemostasis. ${ }^{3}$
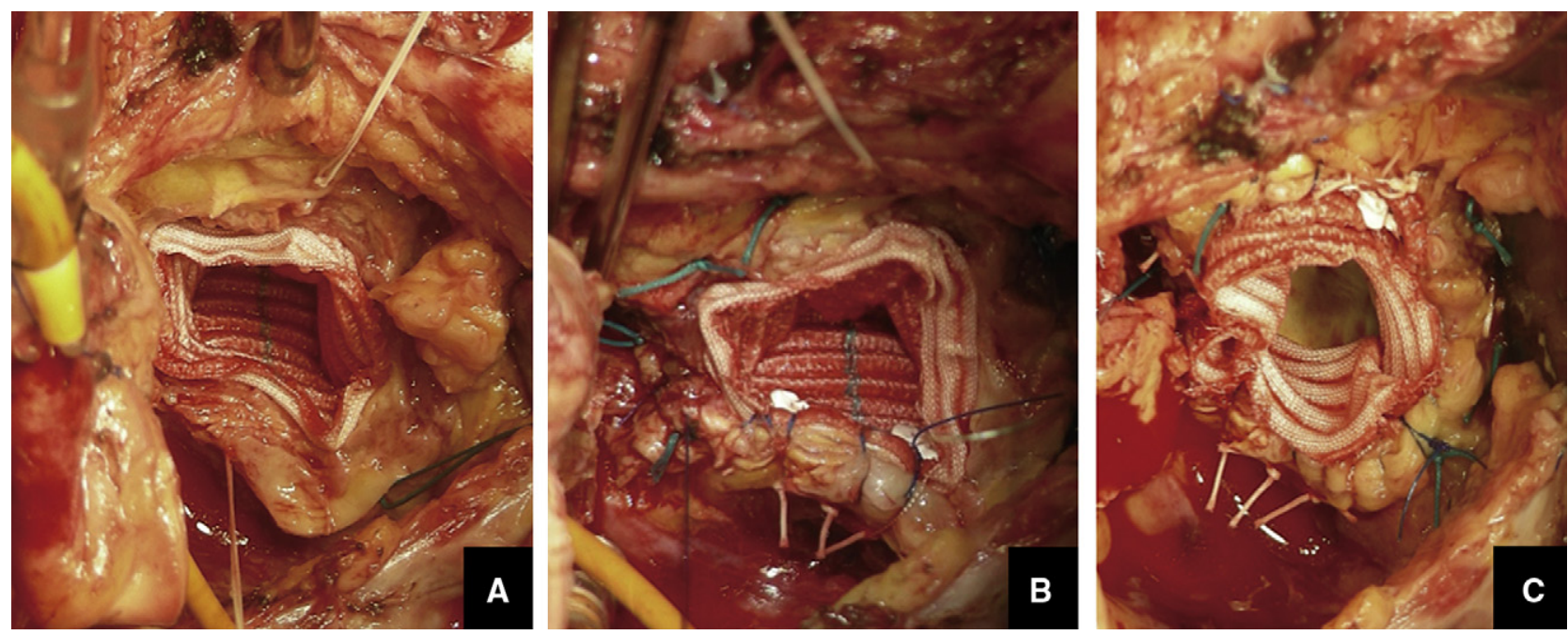

FIGURE 2. Intraoperative view. A, An inverted tube graft is inserted into the left ventricular outflow tract (LVOT), and several horizontal mattress sutures have been placed from inside the inserted graft to the epicardial side. B, Partway through a running over-and-over suture bonding the edge of the LVOT and the inserted graft. C, The inserted tube graft is pulled out from the LVOT, making it right-side-out again. 
Although our graft insertion technique requires graft-to-graft anastomosis between the graft anastomosed to the LVOT and the composite graft, this graft-to-graft anastomosis can be easily performed with continuous over-and-over sutures.

The aortic valve allograft is considered one of the best choices for avoiding recurrence of infection in cases of PVE with extensive tissue destruction. However, in addition to the allograft being hard to come by, an irregular suture line of the aortic annulus after aggressive debridement would make the allograft prone to distortion. In such complicated cases our technique should be a good alternative. When resection of the severe root abscess results in a defect of the intervalvular fibrous body, reconstruction through the aortic root and dome of the atrium is mandatory. We believe our technique can be applied together with atrioventricular reconstruction.

Another advantage of our graft insertion technique is that a valve larger than the LVOT can be inserted in patients with small aortic roots. In such a case the graft anastomosed to the LVOT can be cut on the bias to receive a larger stentless valve or composite graft containing a valve larger than the LVOT, whereas without the connecting graft, the composite graft with the valve would have to be the same diameter as the LVOT.
Complete heart block is a common complication after reoperation on the aortic root with a $10 \%$ to $30 \%$ occurrence rate. ${ }^{1,2,4,5}$ We put our mattress sutures at the lower edge of the trace of the previous valve or at a slightly higher position in the membranous septum compared with other sutures, and this might have led to the complete absence of heart block in this series.

In conclusion, we present a technique that is easy and reliable for reinforcing the proximal anastomosis for difficult reoperations of a damaged aortic root.

\section{References}

1. Malvindi PG, Putte BP, Heijmen RH, Schepens MAAM, Morshuis WJ. Reoperations on the aortic root: experience in 46 patients. Ann Thorac Surg. 2010;89: 81-6.

2. Raanani E, Dacid TE, Dellgren G, Armstrong S, Ivanov J, Feindel C. Redo aortic root replacement: experience with 31 patients. Ann Thorac Surg. 2001;71: 1460-3.

3. Nakamura Y, Tagusari O, Seike Y, Domoto S. Inverted graft insertion technique for apicoaortic bypass. Eur J Cardiothorac Surg. 2010;38:795-7.

4. Szeto WY, Bavaria JE, Bowen FW, Geirsson A, Cornelius K, Hargrove WC, et al. Reoperative aortic root replacement in patients with previous aortic surgery. Ann Thorac Surg. 2007;84:1592-9.

5. Leyh R, Knobloch K, Hagl C, Ruhparwar A, Fischer S, Kofidis T, et al. Replacement of the aortic root for acute prosthetic valve endocarditis: prosthetic composite versus aortic allograft root replacement. J Thorac Cardiovasc Surg. 2004;127: 1416-20.

\title{
How to choose the best available homograft to reconstruct the right ventricular outflow tract
}

\author{
David Kalfa, MD, Loïc Macé, MD, Dominique Metras, MD, and Bernard Kreitmann, MD, Marseille, \\ France
}

Cryopreserved homografts are among the most widely used tools to reconstruct the right ventricular outflow tract (RVOT). Numerous risk factors for homograft degeneration related to the operation, patient, and cardiac disease are clearly established but remain unmodifiable. On the other hand, risk factors related to the homograft by itself (eg, donor, processing, storage) are not consensual and influence the fate of the reconstructed RVOT through the choice of

From the Department of Cardiac and Thoracic Surgery of the La Timone Children's Hospital, Marseille, France.

Disclosures: Authors have nothing to disclose with regard to commercial support.

Received for publication Oct 3, 2010; revisions received Dec 8, 2010; accepted for publication March 1, 2011; available ahead of print April 1, 2011.

Address for reprints: David Kalfa, MD, Marie Lannelongue Hospital, Department of Pediatric Cardiac Surgery, 133 Av De la Résistance, 92350 Le Plessis Robinson,

France (E-mail: davidkalfa@gmail.com).

J Thorac Cardiovasc Surg 2011;142:950-3

$0022-5223 / \$ 36.00$

Copyright (c) 2011 by The American Association for Thoracic Surgery

doi:10.1016/j.jtcvs.2011.03.005 the homograft made by the surgeon at the time of implantation. The objective of this study was to determine the risk factors for homograft dysfunction and failure related to the origin, characteristics, and processing of the homograft to help the surgeon to choose the best available homograft for a given patient.

\section{PATIENTS AND METHODS}

A retrospective study (1993-2009) included 222 consecutive pediatric and adult patients with implantation of a homograft for reconstruction of the RVOT. All homografts came from a local tissue bank and were cryopreserved in nitrogen vapor $\left(-2^{\circ} \mathrm{C} / \mathrm{min}\right.$ to $-5^{\circ} \mathrm{C} / \mathrm{min}$, up to $\left.-150^{\circ} \mathrm{C} / \mathrm{min}\right)$ after processing. Studied end points were homograft dysfunction and homograft failure. Homograft dysfunction was defined on echocardiographic criteria: a peak gradient of $50 \mathrm{~mm} \mathrm{Hg}$ or more or a regurgitation grade at least moderate. Serial transthoracic echographic measurements were performed at discharge and then yearly thereafter by the same in-house cardiologist whenever possible using 2.5-MHz ultrasound transducers (HewlettPackard Sonos 2500 System; Hewlett-Packard Co, Andover, Mass) or by the referring cardiologist in the remaining cases. Maximum velocities across the pulmonary valve were calculated by a continuous-wave Doppler 